\title{
Research Paper: Psychometric Properties of the Persian Version of Self-determination Parent Perception Scale
}

\author{
Elahe Hojati Abed ${ }^{1}$ (D), Malahat Akbarfahimi ${ }^{1 *}$ (D), Narges Shafaroudi ${ }^{1}$ (i), Armin Zareiyan² ${ }^{\text {(D) }}$, Akram Parand ${ }^{3}$ (D), Samaneh Karamali Esmaieli ${ }^{1}$ (D)
}

1. Department of Occupational Therapy, School of Rehabilitation Sciences, Iran University of Medical Sciences, Tehran, Iran.

2. Department of Community Health, School of Nursing, AJA University of Medical Sciences, Tehran, Iran.

3. School of Psychology, Tehran University, Tehran, Iran.

\begin{tabular}{|c|c|}
\hline $\begin{array}{l}\text { Use your device to scan } \\
\text { and read the article online }\end{array}$ & \\
\hline arping & $\begin{array}{l}\text { of the Persian Version of Self-determination Parent Perception Scale Iranian Rehabilitation Journal. 2020; 18(1):23-30. http:// } \\
\text { dx.doi.org/10.32598/irj.18.1.337.2 }\end{array}$ \\
\hline 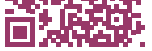 & del'http://dx.doi.org/10.32598/irj.18.1.337.2 \\
\hline
\end{tabular}

Article info:

Received: 10 Jul 2019

Accepted: 10 Oct 2019

Available Online: 01 Mar 2020

\section{Keywords:}

Adolescents, Factor analysis, Parents, Psychometrics, Selfdetermination

\section{A B STRACT}

Objectives: Self-determination is a significant skill in the proper transition from adolescence to adulthood. Parents play an important role in assessing the self-determination of their children. Currently, there is no valid instrument in Iran to assess parents' views about the self-determination of their adolescents. The present study was conducted to determine the psychometric properties of the Persian version of the Self-determination Parent Perception Scale (SDPPS) in an Iranian population.

Methods: In this descriptive psychometric study, the original version of SDPPS was translated using the forward-backward method. The content validity index and content validity ratio of the questionnaire were confirmed by a panel of 15 experts, and its face validity was evaluated among 10 parents of the adolescents. Exploratory factor analysis was conducted on 125 parents of adolescents (aged 14-18 years) who were selected by convenience sampling with maximum variation. Its reliability and internal consistency were also assessed using test-retest and in a group of 17 parents, respectively. The obtained data were analyzed by SPSS V. 18

Results: The items were modified at the face validity stage and approved at the content validity stage. Five factors by explaining $54.14 \%$ of the variance and deleting four items were confirmed at the construct validity stage using exploratory factor analysis. A Cronbach's alpha of 0.93 was obtained for the total scale and 0.79 to 0.85 for the five subscales of the SDPPS. The intra-class correlation coefficient with $95 \%$ CI $(0.82-0.98)$ was 0.83 indicating good reliability of the questionnaire.

Discussion: The Persian version of SDPPS showed acceptable validity and reliability in explaining the self-determination of adolescents with and without disabilities based on the parents' perspectives and can be applied by professionals in rehabilitation centers and those studying on human behavior.

\section{* Corresponding Author:}




\section{Highlights}

- The Persian version of the SDPPS has convenient content and construct validity.

- The Persian version of the SDPPS has proper internal consistency and test-retest reliability.

- The Persian version of the SDPPS is an acceptable, valid, and reliable tool to assess the parents' perception regarding adolescent self-determination.

\section{Plain Language Summary}

Self-determination knowledge and skills are important life skills for success throughout one's life. Parents have unique experiential foundations to evaluate their children's skills and identify areas of strength and the needs for selfdetermination. In this regard, we need to evaluate the self-determination of youth from the perspectives of their parents. In this study, researchers translated and validated an instrument to measure adolescents' self-determination from parents' perception. The results showed that the Self-determination Parent Perception Scale is a reliable measure to assess the parents' perception about adolescents' self-determination in Iranian parents.

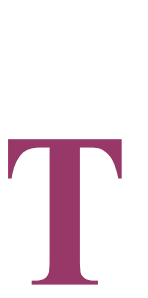

\section{Introduction}

he ability to identify and achieve goals based on knowing yourself and values is defined as self-determination [1]. Rehabilitation Act Amendments of 1998 emphasize the concept of empowerment and the need for informed choice for those with disabilities who need to be more self-determined [2]. Self-determination can promote the capacity of the student with disabilities to control his/her life by enhancing goal setting, problem-solving, decision making, and self-advocacy [3]. Self-determination is associated with the higher educational attainment and positive employment and independent living outcomes [4]. Given the importance of selfdetermination, teachers and parents can play significant roles in promoting self-determination skills in students with disabilities [5, 6]. Parents develop self-determination skills in daily living activities by offering opportunities for their children to set simple goals, solve simple problems, make choices and decisions, and evaluate the outcomes of their decisions [7].

Interestingly, parents, through their specific perceptions and beliefs about self-determination [5] development of a cultural, social, and economic context [7, 8], their parental control style, and quality of their relationships with professionals [9] can play a facilitating or inhibiting role in the self-determination of their children. Moreover, parents' expectations and priorities about their children may be convergent or divergent compared with those of teachers or professionals. Parents, by observing the daily routines of their children at home, in the community, and other places other than school can achieve a unique insight into their children, which can affect their children [10] and help to improve their problem-solving, self-advocacy, leadership, and other skills needed to promote self-determination [5].

Due to the crucial importance of self-determination, several tools have been developed to assess this ability $[11,12]$. Some self-determination tools measure this skill from the perspective of different individuals, such as students, counselors, educators, and parents, and the information obtained from different sources makes it possible to have a more accurate judgment about the adolescents' self-determination. The American Institutes for Research (AIR) Self-determination Scale [13] and the Self-Determination Assessment Battery [14] have developed to assess self-determination. The Self-determination Parent Perception Scale (SDPPS) is a part of the Self-Determination Assessment Battery. This battery is based on the self-determination model, consisting of three scales (Self-Determination Student Scale, Self-Determination Advisor Perception Scale, and SDPPS [14].

Theoretical foundations of the self-determination model were presented by Field and Hoffman in 1994 [15] focusing on the variables associated with self-determination and improving students' awareness, decision-making, goal-setting, and relationships. The model has five components: 1 . know yourself and your context; 2 . value yourself; 3. plan; 4. act; and 5. experience outcomes and learn. The Self-Determination Assessment Battery examines the cognitive, emotional, and behavioral aspects of self-determination. These three scales can be 
used alone or as a battery by individuals, such as parents, counselors, and educators who support the students [14].

Hoffman et al. (2004) developed the Self-Determination Assessment Battery and examined its psychometric properties [14]. Alamri (2017) translated an online version of the SDPPS into the Arabic language. She investigated its internal consistency and reliability, as well as exploratory factor analysis and reported high levels of internal consistency and reliability with Cronbach's alpha of 0.95 . Her findings with Principal Component Analysis resulted in a five-factor model, where $67.30 \%$ of the variance was explained for the SDPPS scale [16].

Despite the vital role of parents in the development of self-determination, less attention has been paid to the parents' attitude regarding self-determination in their children. No tool in Persian has been developed to assess self-determination; therefore, in the present study, the SDPPS was translated and examined in terms of psychometric properties, including the face, content, and construct validity, as well as internal consistency and test-retest reliability.

\section{Methods}

This psychometric study was conducted on a number of experts and parents of five high school students in Tehran, Iran. The parents were selected by convenience sampling. The inclusion criteria were a): being the parent of a high school student aged 14-18 years enrolled in public schools, and b): being able to read and speak in Persian. The sample for construct validity included 150 parents; however, 125 parents (100 mothers and 25 fathers; mean age: $51.34 \pm 7.12$ years) completed the SDPPS.

The SDPPS was developed in 1994 [14] and its online version was updated in 2006 and 2015. This tool was designed to assess self-determination in adolescents aged 14-22 years with or without disabilities by parents. This 30 -item questionnaire was administered to the parents. The parents scored his/her adolescents on a five-point Likert scale from $0=$ low to $5=$ high on a variety of components related to the model. It consists of five subscales and the score of each subscale reflects the strengths or weaknesses in different aspects of self-determination. The total score of self-determination is obtained by the sum of the scores of these subscales. A high score in the SDPPS indicates that from parents' perception, their adolescents have a high level of self-determination. Cronbach's alpha was calculated as 0.95 and construct validity and reliability of the scale were confirmed [14].
The Persian version of SDPPS was prepared by translating the original scale in accordance with the International Quality of Life Assessment (IQOLA) project [17]. Permission to translate was acquired from the scale developer. The scale was translated from English to Persian by two translators proficient in the English language and one was familiar with the construct. The early Persian version of the SDPPS was prepared by an expert panel. Then, it was back-translated into English by an expert translator with 10 years of experience in education who was blinded to the original version. The research team compared this English version with the original one and confirmed the consistency of content, conceptual equivalence, and quality of the translation. The scale developers were informed about the process of translation.

In the next stage, the psychometric properties of the SDPPS were investigated. Its face validity was determined by 10 parents in the target group. The Content Validity Index (CVI) was assessed by a 15-member panel consisted of 13 occupational therapists and 2 psychologists in terms of necessity, simplicity, relevance, and clarity of each item. . To assess the reliability of the SDPPS, after making an agreement with the high schools' principals, a letter was sent to the parents, in which the research objective was described and they were invited to participate in the study by attending a meeting at schools. Parents who consented to participate completed the questionnaire. Repeatability of the SDPPS was assessed in a group of 17 parents at a two-week interval.

The descriptive data are reported as means and standard deviations. To determine the validity of the SDPPS, content Validity Ratio (CVR) and CVI were used. The construct validity was examined with exploratory factor analysis through the methods of Principal Axis Factoring (PAF) and Promax rotation. The internal consistency was investigated by Cronbach's alpha, and reliability was examined by test-retest using the intra-class correlation coefficient $(95 \% \mathrm{CI})$. Data were analyzed using SPSS v. 18 [18].

\section{Results}

For confirming the face validity of the SDPPS, each item was examined by three options regarding the fit and relevance of the items, ambiguity and inadequate perceptions, and difficulty in understanding concepts from the viewpoint of the target group. Participants stated that they have had no problems in reading and understanding the items. 
Table 1. Results of the Cronbach's alpha and the test-retest reliability for the Self-determination Parent Perception Scale (SDPPS) and its subscales

\begin{tabular}{cccc}
\hline Factor & Cronbach's Alpha & Intra-class Correlation Coefficient & Number of Items \\
\hline Know yourself & 0.83 & 0.82 & 3 \\
\hline Value yourself & 0.83 & 0.95 & 6 \\
\hline Plan & 0.79 & 0.88 & 4 \\
\hline Act & 0.82 & 0.98 & 7 \\
\hline Experience outcomes and learn & 0.85 & 0.95 & 6 \\
\hline Total & 0.93 & 0.83 & 26 \\
\hline
\end{tabular}

To determine the content validity, CVI and CVR were calculated for each item. According to the Lawshe table, 15 subject-matter experts were participated and the CVR approval score for each item was considered equal to 0.49 or higher with a $95 \%$ confidence interval [19]. This ratio was within the range of $0.6-1$ with an average of 0.93. The CVI of the SDPPS ranged from 0.8 to 1 , which was 0.9 for the whole scale [20]. No item was eliminated at this stage. Nineteen items were detected by the experts without any controversy and maintained in the scale. In the remaining 11 items (items 1, 6, 12, 14, 16, 18, 19, $20,21,29$, and 30), slight changes were made to improve their clarity according to the experts' opinions; for example, the initial translation of item 1 was "Explain dreams or what is likely to happen?" that was changed to "Expresses his/her dreams or wishes?" (Table 3).

To determine the construct validity, exploratory factor analysis was used [21]. The extraction method of PAF with Promax rotation was used to assess 125 collected questionnaires. The Kaiser-Meyer-Olkin measure verified the sampling adequacy for the analysis $(\mathrm{KMO}=0.883)$. The Bartlett's test of sphericity $\left(\chi^{2}\right.$
$325)=1694.082, \mathrm{P}<0.000$ ) rejected the null hypothesis $(\mathrm{P}<0.001)$ and the correlation matrix was equal to the identity matrix and the correlations between items were sufficiently large for exploratory factor analysis [18]

The Kaiser criterion was used to extract the factors. The cutoff point for the significance of item factor loadings was considered 0.4 leading to the extraction of five factors. The results of the rotational correlation matrix table showed that the five factors could explain $54.17 \%$ of the variance (Table 1). The items 13, 14, 22, and 23 were removed because they did not load on any factors (Table 2).

The first factor consisted of three items with factorial loadings ranging from 0.559 to 0.913 ; the second factor included six items with factorial loadings of 0.439 to 0.776; the third factor included four items with factorial loadings ranging from 0.408 to 0.656 ; the fourth factor consisted of seven items with factorial loadings of 0.408 to 0.796 ; and the fifth factor had six items with factorial loadings of between 0.454 and 0.900 (Table 2). According to Table 1, all standardized factorial loadings were significant at the level of 0.05 [22].

Table 2. Total explained variance of the Persian version of the Self-determination Parent Perception Scale (SDPPS)

\begin{tabular}{ccccccc}
\hline \multirow{2}{*}{ Factor } & \multicolumn{3}{c}{ Initial Eigenvalues } & \multicolumn{3}{c}{ Extraction Sums of Squared Loadings } \\
\cline { 2 - 6 } & Total & Variance\% & Cumulative\% & Total & Variance \% & Cumulative \% \\
\hline 1 & 9.781 & 37.620 & 37.620 & 9.335 & 35.902 & 35.902 \\
\hline 2 & 9.311 & 8.890 & 46.509 & 1.875 & 7.210 & 43.112 \\
3 & 1.623 & 6.241 & 52.750 & 1.190 & 4.578 & 47.690 \\
4 & 1.477 & 5.682 & 58.432 & 1.013 & 3.896 & 51.586 \\
5 & 1.103 & 4.244 & 62.676 & 0.674 & 2.593 & 54.179 \\
\hline
\end{tabular}


Table 3. Results of the exploratory factor analysis of the Self-determination Parent Perception Scale (SDPPS) ( $\mathrm{n}=125)$

\begin{tabular}{|c|c|c|c|c|c|c|}
\hline Items & 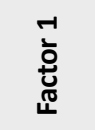 & 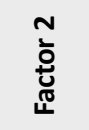 & 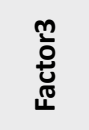 & 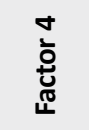 & 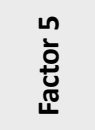 & $\begin{array}{c}\text { Communalities } \\
\text { (Extraction) }\end{array}$ \\
\hline 1. Express dreams or possibilities? & & & & 0.440 & & 0.253 \\
\hline 2. Know her/his strengths? & 0.788 & & & & & 0.660 \\
\hline 3. Know his/her weaknesses? & 0.913 & & & & & 0.686 \\
\hline 4. Know his/her preferences? & 0.559 & & & & & 0.652 \\
\hline 5. Know his/her needs? & & 0.530 & & & & 0.536 \\
\hline 6. Explore options? & & 0.642 & & & & 0.541 \\
\hline 7. Make decisions? & & 0.776 & & & & 0.403 \\
\hline 8. Accept and value herself/himself? & & 0.693 & & & & 0.533 \\
\hline 9. Find strength that comes from acknowledging weaknesses? & & & 0.439 & & & 0.561 \\
\hline 10. Recognize her/his rights? & & 0.462 & & & & 0.462 \\
\hline 11. Recognize her/his responsibilities? & & & & & 0.542 & 0.633 \\
\hline 12. Take care of herself/himself? & & 0.526 & & & & 0.616 \\
\hline
\end{tabular}

13. Set goals?

14. Plan?

15. Anticipate consequences?

0.526

0.627

16. Demonstrate creativity?

0.656

0.570

17.Take risks?

0.510

18.Demonstrate appropriate communication skills?

0.482

19. Access resources and support

0.408

0.511

20. Negotiate?

0.670

0.653

21. Use humor?

0.796

22. Deal appropriately with conflict?

23.Deal appropriately with criticism?

24.Initiate actions?

25.Persist until a goal is accomplished?

26.Compare outcomes to expectations?

27. Evaluate his/her performance?

28. Acknowledge her/his successes?

29. Adjust behavior to improve performance?

30. Express self-determination?
0.569

0.456

0,454
0.464 
The internal consistency of the SDPPS was determined by Cronbach's alpha for the total scale and subscales (Table 1). As can be observed, the Cronbach's alpha coefficient was 0.93 for the whole questionnaire and they were at acceptable levels for the subscales. The IntraClass Correlation Coefficient (ICC) for each subscale score and the total score was calculated and the results are shown in Table 1.

\section{Discussion}

The present study investigated the psychometric properties of the SDPPS, a questionnaire for assessing selfdetermination of high school students from the perspective of their parents in an Iranian population. This study was conducted on 125 parents of adolescents aged 14-18 years living in Tehran. The findings suggested that the Persian version of SDPPS has acceptable reliability and validity for estimating the degree of self-determination in adolescents through the perception of their parents. The face validity of the SDPPS based on laypersons' comments and parents' opinions was acceptable and appropriate in the Iranian population for assessing the selfdetermination from parents' perspective.

For determining the content validity, the present study was performed based on the Lawshe et al. method [20], based on which the necessity of all questions was confirmed and no question was omitted. Based on this model, item 1 (“express dreams or possibilities?") and item 19 ("access resources and support?") did not have enough simplicity and item 6 ("explore options?"), item 12 (“take care of herself/himself?"), item 14 (“plan?"), item 16 ("demonstrate creativity?"), item 18 ("demonstrate appropriate communication skills?"), item 20 (“negotiate?"), item 21 ("use humor?"), item 29 (“adjust behavior to improve performance?"), and item 30 ("express self-determination?") did not have enough clarity; therefore, some modifications were made for simplifying and rendering the sentences according to the comments of the experts and parents. Moreover, the concept of self-determination in item 30 was described for better clarity.

The Cronbach's alpha value was acceptable for all the SDPPS subscales. This value was high for all five subscales and the total scale (0.93), demonstrating the high level of correlation between the subscales. A Cronbach's alpha value of 0.70 is generally sufficient to indicate the internal consistency and the value of 0.90 is considered as very good [21]. In the previous studies, Hoffman et al. (2004) and Alamri (2017) reported the Cronbach's alpha of 0.95 for the English version [14] and the Arabic version [16] of the SDPPS, respectively.

The test-retest reliability through ICC with 95\% CI showed the lowest ICC (for the "knowing yourself" subscale) of 0.82 , and the highest ICC (for the "action" subscale) of 0.98; therefore, the findings indicated the good reliability and repeatability of the Persian version of SDPPS.

The results of the present study based on the exploratory factor analysis showed that the Persian version of SDPPS has a 5-factor structure similar to the original version of the questionnaire. The original version is a 30 -item scale with the subscales, such as know yourself, value yourself, plan, action, and experience outcomes and learn with seven, five, four, nine, and four items, respectively. However, in this study, after discarding four items and changing the content of some items, each subscale with minor modification was matched with the exploratory factor analysis of the Field et al. study [14]. In this study, the reliability of the five subscales was in the range of $0.79-0.93$. It can be concluded that the Persian version of SDPPS with 26 items has high validity and reliability. The omitted items included item 13 (“set goals?"), item 14 (“plan?"), item 22 (“deal appropriately with conflicts?"), and item 23 (“deal appropriately with criticisms?”)

It is recommended to conduct a confirmatory factor analysis for the SDPPS in future studies and evaluate the validity and reliability of this version in other cities of Iran with a larger sample size. Similar studies in parents of children with disabilities can also result in some interesting findings. In future studies, factors affecting self-determination, such as creativity can be studied in Iranian schools. Studying the psychometric properties of the SDPPS in older samples with sever cognitive impairments compared with our subjects (mean age: 15.5 years) can also be useful.

\section{Conclusion}

According to the findings of this study, the Persian version of SDPPS is a valid and reliable scale with good psychometric properties. It is recommended to use this scale by therapists in clinical settings. The valid and reliable assessment tools reporting parents' perspectives help therapists to plan family-centered interventions for improving self-determination. The results of this study will be useful for professionals, such as psychologists, teachers, occupational therapists, rehabilitation practitioners, and sociologists studying on human behavior. 


\section{Ethical Considerations}

\section{Compliance with ethical guidelines}

This study was approved by the Ethics Committee of Iran University of Medical Sciences (Code: 9321525001IR.IUMS.REC.1396).

\section{Funding}

This article was extracted from a $\mathrm{PhD}$. dissertation of the first author and was funded by the Iran University of Medical Sciences.

\section{Authors' contributions}

Conceptualization and Supervision: Malahat Akbarfahimi, Narges Shafaroudi; Data analysis: Elahe Hojati Abed, Armin Zareian; Writing the manuscript: Elahe Hojati Abed, Samaneh Karamali Esmaieli; and Writing, review, reading, editing, and approving the final version of the manuscript: All authors.

\section{Conflict of interest}

The authors declared no conflict of interests.

\section{Acknowledgments}

The authors sincerely thank the high school staff, college faculty members, and parents contributing to this research.

\section{References}

[1] Field S, Hoffman A, Posch M. Self-determination during adolescence a developmental perspective. Remedial and Special Education. 1997; 18(5):285-93. [DOI:10.1177/074193259701800504]

[2] Wehmeyer ML, Palmer SB. Adult outcomes for students with cognitive disabilities three-years after high school: The impact of self-determination. Education and Training in Developmental Disabilities. 2003; 38(2):131-44.

[3] Wehmeyer ML. Self-determination and the empowerment of people with disabilities. American Rehabilitation. 2004; 28:22-9.

[4] Wehmeyer ML, Palmer SB, Shogren K, Williams-Diehm K, Soukup JH. Establishing a causal relationship between intervention to promote self-determination and enhanced student selfdetermination. The Journal of Special Education. 2013; 46(4):195210. [DOI:10.1177/0022466910392377] [PMID] [PMCID]

[5] Carter EW, Lane KL, Cooney M, Weir K, Moss CK, Machalicek W. Parent assessments of self-determination importance and performance for students with autism or intellectual dis- ability. American Journal on Intellectual and Developmental Disabilities. 2013; 118(1):16-31. [DOI:10.1352/1944-7558118.1.16] [PMID]

[6] Shogren KA, Garnier Villarreal M, Dowsett C, Little TD. Exploring student, family, and school predictors of selfdetermination using NLTS2 data. Career Development and Transition for Exceptional Individuals. 2016; 39(1):23-33. [DOI:10.1177/2165143414546685]

[7] Zhang D, Landmark L, Grenwelge C, Montoya L. Culturally diverse parents' perspectives on self-determination. Education and Training in Autism and Developmental Disabilities. 2010; 45(2):175-86.

[8] Shogren KA. Culture and self-determination: A synthesis of the literature and directions for future research and practice. Career Development for Exceptional Individuals. 2011; 34(2):115-27. [DOI:10.1177/0885728811398271]

[9] Field S, Hoffman A. Lessons learned from implementing the steps to self-determination curriculum. Remedial and Special Education. 2002; 23(2):90-8. [DOI:10.1177/074193250202300205]

[10] Hojati Abeh E, Mirzaie H, Aahmadi A. Cognitive behavioral stress management program and mothers of children with oppositional defiant disorder. Iranian Rehabilitation Journal. 2014; 12(3):43-7.

[11] Field S, Hoffman A. Self-determination in secondary transition assessment. Assessment for Effective Intervention. 2007; 32(3):181-90. [DOI:10.1177/15345084070320030601]

[12] Verdugo MA, Vicente E, Fernández-Pulido R, Gómez-Vela M, Wehmeyer ML, Guillén VM. A psychometric evaluation of the ARC-INICO self-determination scale for adolescents with intellectual disabilities. International Journal of Clinical and Health Psychology. 2015; 15(2):149-59. [DOI:10.1016/j. ijchp.2015.03.001] [PMID] [PMCID]

[13] Shogren KA, Wehmeyer ML, Palmer SB, Soukup JH, Little TD, Garner N, et al. Understanding the construct of self-determination: Examining the relationship between the Arc's SelfDetermination Scale and the American Institutes for Research Self-Determination Scale. Assessment for Effective Intervention. 2008; 33(2):94-107.[DOI.10.1177/1534508407311395]

[14] Hoffman A, Field S, Sawilowsky S. Self-Determination Assessment Battery. User's guide. Center for Self-Determination and Transition: Promoting Resiliency and Well-being Throughout the Lifespan College of Education, Wayne State University [Internet]. 2004 [Updated 2008 May 6]. Available from: https:/ / coe.wayne.edu/self-determination/faculty.php

[15] Field S, Hoffman A. Development of a model for self-determination. Career Development for Exceptional Individuals 1994; 17(2):159-69. [DOI:10.1177/088572889401700205]

[16] Alamri M. Reliability and validity of an Arabic version of the self-determination assessment--Internet (SDAi) [PhD. dissertation]. Detroit: Wayne State University. 2017.

[17] Montazeri A, Goshtasebi A, Vahdaninia M, Gandek B. The short form health survey (SF-36): Translation and validation study of the Iranian version. Quality of Life Research. 2005; 14(3):875-82. [DOI:10.1007/s11136-004-1014-5] [PMID]

[18] Field A. Discovering statistics using IBM SPSS statistics. London: Sage Publication; 2013. 
[19] Lawshe CH. A quantitative approach to content validity. Personnel Psychology. 1975; 28(4):563-75. [DOI:10.1111/j.1744-6570.1975.tb01393.x]

[20] Polit DF, Beck CT, Owen SV. Is the CVI an acceptable indicator of content validity? Appraisal and recommendations. Research in Nursing \& Health. 2007; 30(4):459-67. [DOI:10.1002/nur.20199] [PMID]

[21] Tabachnick BG, Fidell LS. Using multivariate statistics. USA: Allyn \& Bacon/Pearson Education; 2007.

[22] Ho R. Handbook of univariate and multivariate data analysis with IBM SPSS. New York: Chapman and Hall/CRC 2013. [DOI:10.1201/b15605] 